\title{
Mortality profile and out come analysis in level two SNCU in tribal medical college district Adilabad Telangana
}

\author{
Suryakant Mundlod ${ }^{1}$, Smita Thakkarwad ${ }^{2 *}$ \\ ${ }^{1,2}$ Associate Professor, ${ }^{1}$ Dept. of Paediatric, ${ }^{2}$ Dept. of OBGY, 1,2 PCMC-Yashwantrao Chavan Memorial Hospital, Pimpri, Pune, \\ Maharashtra, India
}

*Corresponding Author: Smita Thakkarwad

Email: dr_surya@rediffmail.com

\begin{abstract}
Introduction: Neonatal period is a very vulnerable period of life due to many problems. India alone contributes to about $25 \%$ of neonatal mortality around the world. In spite of advances in perinatal and neonatal care, neonatal mortality is still high in developing countries. This study was undertaken to study the disease pattern and outcome of neonates admitted to the sick neonatal intensive care unit (SNCU) of a tribal teaching hospital Adilabad

Study Design: Retrospective study of medical records for 1 year (January 2015-December 2015) from SNCU Softwere.

Materials and Methods: Neonates admitted to SNCU, Adilabad Rajiv Gandhi institute of medical sciences included in the study; the data which were recorded in predesigned proforma in SNCU software. The data were analyzed using appropriate statistical tool.

Results: A total of 1326 neonates were admitted to SNCU during the study period, 147neonates left against medical advice, 51 were referred to other centre hence excluded from analysis. The ratio of the males to female admitted was $1.42: 1$. In this study, overall mortality rate was $13.7 \%$. Most of the deaths were due to birth asphyxia (49.55\%), RDS (38\%), neonatal sepsis (10.6\%), Neonates with birth weight <1500 g had poor outcome compared to neonates with birth weight more than $2500 \mathrm{~g}$.

Conclusion: This study identified birth asphyxia, RDS and neonatal sepsis as the major contributors to the neonatal mortality. Improving antenatal care, maternal health improve neonatal outcome.
\end{abstract}

Keywords: Birth asphyxia, Neonatal mortality, Neonatal sepsis, RDS.

\section{Introduction}

The neonatal period is a very vulnerable period of life due to many problems, which in most of the cases is preventable. ${ }^{1,2}$ Of the 25 million babies born in India every year one million die, India alone contributes to $25 \%$ of neonatal mortality around the world. As per the National Family Health Survey ${ }^{3}$ report, current neonatal mortality rate (NMR) in India is 39 per 1000 live births, neonatal deaths accounts for nearly $77 \%$ of all infant deaths $(57 / 1000)$ and nearly half of under-five child deaths (74/1000). ${ }^{3}$ Preterm and low birth weight (LBW) babies are at increased risk of perinatal mortality and morbidity. ${ }^{4}$ As per the report sheet published in the Lancet, the major direct causes of neonatal mortality are pre-term birth $(27 \%)$, infection (26\%), asphyxia (23\%), congenital anomalies $(7 \%)$, others $(7 \%)$, tetanus $(7 \%)$, and diarrhoea $(3 \%){ }^{5}$ There are very scanty data which are available regarding the neonatal mortality and morbidity pattern in India. Advancement in perinatal and neonatal care have significantly helped in reducing NMR in developed countries, but the mortality and morbidity are still high in developing countries. ${ }^{6}$ This study was undertaken to study the disease pattern and outcome of neonates admitted to the special newborn care unit (SNCU) of a secondary care teaching hospital located in Adilabad district, a tribal area in Telangana state, India.

\section{Materials and Methods}

This hospital based retrospective study was carried out in the SNCU, Department of Pediatrics, at Rajiv Gandhi Institute of Medical Sciences, Adilabad, Telangana, India, for a period of 1 year from January 2015 to December 2015. 1. Our SNCU caters to the population of Adilabad district and referral from neighboring areas like kinwat of Maharashtra state. Approximately 6500 deliveries are conducted per year in the hospital; the majority of patients belong to below poverty line income group. Our SNCU has bed strength of 20, facility for phototherapy, surfactant administration, exchange transfusion, BUT no ventilation care are available. A retrospective case record review and analysis of all the newborn babies admitted to the SNCU during the study period was done and neonates satisfying inclusion and exclusion criteria were included in the study.

\section{Inclusion criteria}

All neonates admitted to SNCU

\section{Exclusion criteria}

Neonates who left hospital against medical advice (LAMA) and neonates who were referred due to non-availability of ventilator support and surgical intervention were excluded from the study. These neonates were categorized as inborn if delivered in the Medical college Hospital and as outborn if born outside. The data were recorded in predesigned Proforma.

\section{Statistics}

Data collected were compiled and entered in MS Excel spreadsheet and analyzed using appropriate statistical tools in Open Epi statistical software. 


\section{Results}

A total number of babies admitted to SNCU during the Study period was 1326 of which 147 neonates LAMA and 51 neonates were referred to other centres hence these Neonates were excluded from the study. A total of 1128 Neonates were included for the data analysis. Out of this $58.78 \%$ (663) were male and 41.22 (465) were females, ratio is $1.42: 1$. Of the total admissions 62.5\% (706) were inborn neonates and $37.4 \%$ (422) were outborn neonates (Table 1). 40.9\% (462/1128) neonates had birth weight $>2500 \mathrm{~g}, 42.5 \%$ (480/1128) of neonates belonged to LBW category (1500$2499 \mathrm{~g}), 14.1 \%(160 / 1128)$ of neonates belonged to very LBW (VLBW) group (1499-1000 g), 2.3\% (26/1128) of neonates were of extremely LBW (ELBW) category $(<1000$ g). On applying one sample Chi-square test to see the observed frequency distribution in males and females neonates overall admitted to SNCU, it was found to be statistically significant $(P<0.001)$. In this study, overall SNCU mortality rate was $13.7 \%$ (155/1128). The mortality rate in inborn neonates was $54.8 \%(62 / 113)$ whereas mortality rate in out born neonates was $55.1 \%$ (51/113), the difference in mortality rate between inborn and outborn neonates was statistically insignificant cant $(P=0.284)$. The mortality in males was $13.0 \%(86 / 155)$, in females was $14.8 \%(69 / 155)$, the difference in the mortality rate among male and female neonates was statistically insignificant cant $(P=0.596)$. The major causes for mortality were hypoxic ischemic encephalopathy/ Birth asphyxia 36.1, RDS (27.7.0), and, prematurity is still on higher side $(21.9 \%)$, neonatal sepsis $(7.7 \%$ ) (Table 3). On comparing survival among different birth weight groups (Table 4), it was seen that there was statistically significant difference between VLBW and normal birth weight group $(P \leq 0.05)$, and between ELBW and normal birth weight group $(P \leq 0.05)$. However, there was no statistically significant difference in survival among LBW and normal birth weight group $(P=0.368)$. It was observed that the duration of time between admission and death was $<1$ day in $61.6 \%$ of deaths $(45 / 155)$ followed by 1 3 days in $14.9 \%$ of deaths $(87 / 155)$.

Table 1: Admission by gender

\begin{tabular}{|l|c|c|c|}
\hline & Total & Male & Female \\
\hline Inborn & 706 & 432 & 271 \\
\hline Outborn & 422 & 230 & 189 \\
\hline
\end{tabular}

Table 2: Mortality comparison by weight on admission

\begin{tabular}{|l|c|c|c|c|c|}
\hline & Total & $<\mathbf{1 0 0 0}$ Gms & $\mathbf{1 0 0 0 - 1 4 9 9}$ Gms & $\mathbf{1 5 0 0 - 2 4 9 9}$ Gms & >=2500 Gms \\
\hline Admission & 1123 & 26 & 160 & 478 & 459 \\
\hline Mortality & 155 & 17 & 37 & 54 & 47 \\
\hline
\end{tabular}

Table 3: Cause of death profile: SNCU RIMS Adilabad, TS

\begin{tabular}{|l|c|c|c|}
\hline Cause of Death profile & Inborn & Out born & Percentage \\
\hline HIE / Moderate-Severe Birth Asphyxia & 33 & 23 & $56(36.1 \%)$ \\
\hline Meconium Aspiration Syndrome & 2 & 0 & $2(1.3 \%)$ \\
\hline Respiratory Distress Syndrome & 21 & 22 & $43(27.7 \%)$ \\
\hline Prematurity (<28 weeks of Gestation) & 24 & 10 & $34(21.9 \%)$ \\
\hline E.L.B.W. (Wt. less than 1000g) & 1 & 4 & $5(3.2 \%)$ \\
\hline Sepsis & 6 & 6 & $12(7.7 \%)$ \\
\hline Any Other & 1 & 2 & $3(1.9 \%)$ \\
\hline & 78 & 67 & $100 \%$ \\
\hline
\end{tabular}

Table 4: SNCU outcome in different birth weight group

\begin{tabular}{|l|c|c|c|}
\hline \multicolumn{1}{|c|}{ Birth weight SNCU } & SNCU admission & Deaths (\%) & Percentage of death is each group (\%) \\
\hline More than $2500 \mathrm{~g}$ & $462(41.0)$ & $47(10.2)$ & 10.1 \\
\hline LBW $(1500-2499 \mathrm{~g})$ & $480(42.6)$ & $54(11.3)$ & 11.2 \\
\hline VLBW $(1000-1499 \mathrm{~g})$ & $160(14.2)$ & $37(23.1)$ & 23.1 \\
\hline ELBW $(<1000 \mathrm{~g})$ & $26(2.3)$ & $17(65.4)$ & 65.3 \\
\hline Total & $1128(100)$ & $155(13.7)$ & 13.7 \\
\hline
\end{tabular}




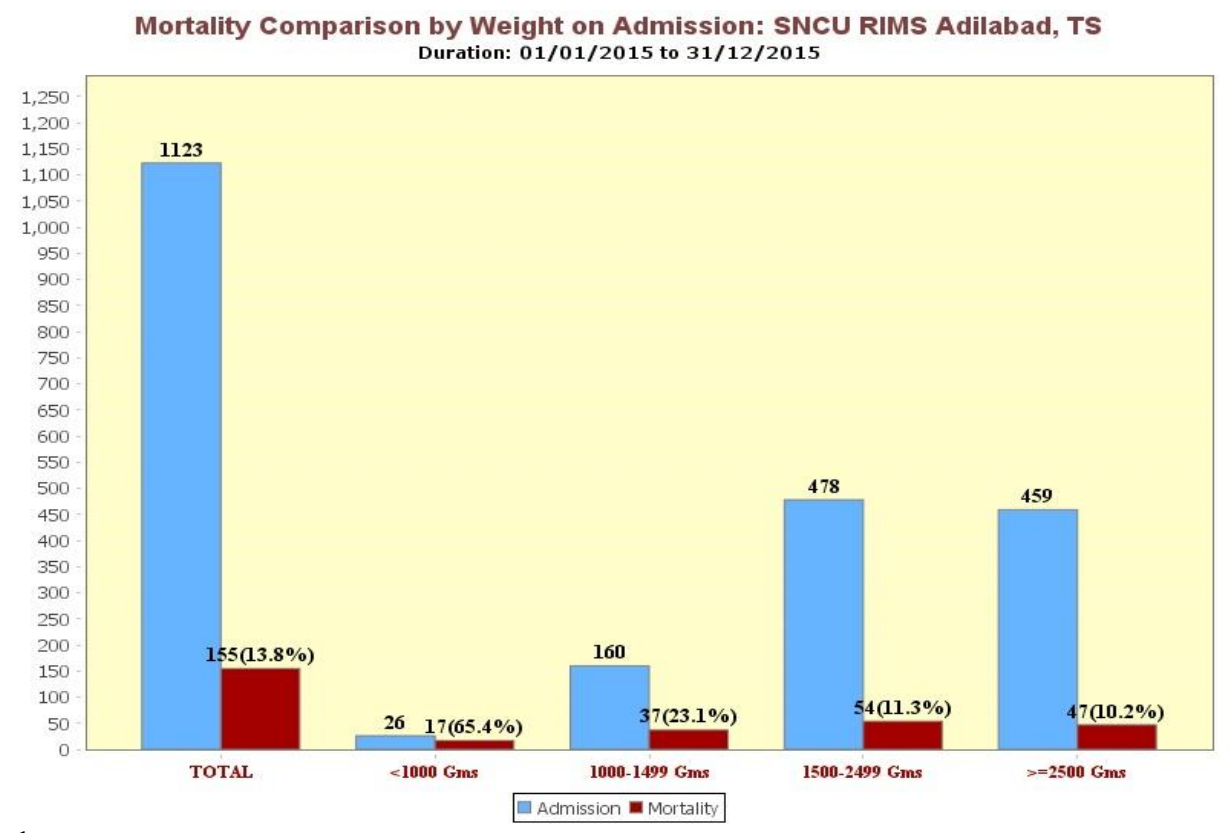

Fig. 1

\section{Discussion}

This study was conducted to delineate the outcome and factors leading to mortality of neonates admitted to SNCU of secondary care teaching hospital. Precise data regarding mortality pattern for SNCU admission are useful for many reasons.

In present study the admissions of male babies were more than that of female babies. It is due to the biological vulnerability of male gender and may be due to the preference of male child in the society. Similar findings were reported from various studies conducted in different parts of India. ${ }^{7-13}$

In our study, total of 1326 neonates were admitted of which $62.5 \%$ neonates were inborn and rest were outborn babies (37.4\%), male preponderance of admission to SNCU was note.

According to the United Nation Children's Fund (UNICEF), "The state of world's children's report $28 \%$ of neonates were born with low birth weight in India. ${ }^{13} \mathrm{But}$ in our study $42.5 \%$ of neonates were low birth weight and $28.58 \%$ of neonates are born prematurely. This may probably be due to poor maternal health condition, low socio-economic status and less visits to health care facility. A study conducted by Gaucham et al. in Nepal reported that neonatal jaundice, sepsis and perinatal asphyxia as being commonest indication for admission to NICU. According to national neonatal perinatal database (NNPD) sepsis (36\%) is the most common morbidity responsible for admission followed by prematurity $(26.5 \%)$ and perinatal asphyxia $(10 \%) .{ }^{11}$ Birth asphyxia is an important cause of neonatal morbidity and mortality, its incidence in our study is $49.55 \%$ which is similar to findings of Chandra et al. RDS acts as an important cause for morbidity and mortality especially among LBW and preterm babies. Mortality rate observed in our study is $13.7 \%$. The most common causes of mortality were birth asphyxia (36.1\%), RDS (27.7\%), prematurity (21.9\%) Neonatal sepsis (7.7\%).Similar pattern of outcome has been reported by study conducted by Rashid et al. ${ }^{14}$ In contrast the study report published by ICMR reports sepsis (32.8\%) as the major cause for neonatal mortality followed by birth asphyxia (22.3\%) and prematurity (16.8\%). ${ }^{15}$ In the study done at JIPMER, sepsis was the cause for death in $52.3 \%$ of followed by birth asphyxia and injuries (29.23\%). Majority of deaths in our study was attributable to birth asphyxia and RDS, this may probably be due to poor antenatal care, malnourished pregnant women, less availability of health facility, delivery by untrained professional and delay in referral from peripheral hospitals. Birth weight $<1500 \mathrm{~g}$ were associated with high number of mortality in preterm neonates.

\section{Conclusion}

According to this study birth asphyxia, RDS and neonatal sepsis are leading causes of mortality in newborns. In spite of many advances in neonatal care above factors still continue to be the leading causes of mortality in neonates. The majority of morbidities and subsequently the mortalities can be prevented by improving antenatal care, maternal health, timely intervention, referring at appropriate time to tertiary care centres for high risk cases, preventing preterm deliveries and care of neonates at centres with facility. This study has some limitations, as this was a hospital based retrospective study, the cause of death was determined using the data available in case record sheets, Neonates who LAMA and those who were referred to other centres due to nonavailability of ventilator support and surgical intervention were excluded from study and could hence modify the results. As the majority of the patients presenting to us belong to low socio-economic status, the results from this study cannot be a complete reflection of the problem in the community as a whole.

\section{Source of funding}

None. 


\section{Conflict of interest}

None.

\section{References}

1. Behl L, Grover N and Kaushik SL. Perinatal and neonatal mortality: A hospital based study. Indian Paediatr 1998;35:683-4.

2. Kapoor RK, Srivatsava AK, Mishra PK, Sharma B, Thakur S, Srivatsava KL. Perinatal Mortality in Urban Slums in Lucknow. Indian Paediatr 1996;33:19-23.

3. Zupan J, Aahaman E. Perinatal mortality for the Geneva: estimates developed by WHO. Geneva: World Health Organisation.

4. Bryce J, Bishi-pinto C, Shibuya K, Balck RE, WHO estimates the cause of death in children. Lancet 2005;365:1147-52.

5. Registrar general and census commissioner India. Sample Registration System Bulletin 2016. Ministry of Home Affairs, Government of India, 2016

6. Lawn JE, Cousens S, Zupan J. 4 million neonatal deaths when? Where? Why? Lancet 2005;365:1147-52.

7. Saharia N, Deka A, Vivekananda MS. Mortality and morbidity pattern of neonatal ICU of Guwhati Medical College and Hospital. IOSR-JDMS. 2016;15:73-5.

8. Sridhar PV, Thammanna PS, Sandeep M. Morbidity pattern and hospital outcome of neonates admitted in a tertiary care Teaching Hospital, Mandya. Int J Sci Stud. 2015;3(6):126-9.

9. Modi R, Modi B, Patel JK, Punitha KM. Study of the morbidity and the mortality pattern in the neonatal intensive care unit at a tertiary care teaching hospital in Gandhinagar District, Gujarat, India. J Res Med Den Sci 2015;3(3):208-12.

10. Malik S, Gohiya P, Khan IA. Morbidity profile and mortality of neonates admitted in Neonatal Intensive Care Unit of a
Central India Teaching Institute: A prospective observational study. J Clin Neonatol 2016;5:168-73.

11. Babu MC, Prakash PS, Prasanna CL. Neonatal morbidity and mortality patterns of babies admitted in SNCU @ ACSR Government Medical College, Nellore, Andhra Pradesh. J Evol Med Dent Sci 2018;7(02):203-6.

12. Kumar MK, Thakur S, Singh B. Study of the morbidity and the mortality patterns in the neonatal intensive care unit at a tertiary care teaching hospital in Rohtas District, Bihar, India. $J$ Clin Diagnos Res 2012;6(2):282-5.

13. UNICEF. The state of the world's children, 2010. New York: UNICEF 2010:92-5. Available at https://www.unicef.org/rightsite/sowc/pdfs/SOWC_ Spec\%20Ed_CRC_Main\%20Report_EN_090409.p

14. Rashid A, Ferdous S, Chowdhury T, Rahman F. The morbidity pattern and the hospital outcome of the neonates who were admitted in a tertiary level hospital in Bangladesh. Bangladesh J Child Health 2003;27:10-3.

15. ICMR Young Infant Study Group. Age profile of neonatal deaths. Indian Pediatr 2008;45:991-4.

How to cite this article: Mundlod S, Thakkarwad S. Mortality profile and outcome analysis in level two SNCU in tribal medical college district Adilabad Telangana. Int $J$ Med Paediatr Oncol 2019;5(4):125-8. 